\title{
QUESTÃO SOCIAL E RELAÇÕES ÉTNICO-RACIAIS NO BRASIL
}

\author{
Cláudia Alves Durans \\ Universidade Federal do Maranhão (UFMA)
}

\section{QUESTÃO SOCIAL E RELAÇÕES ÉTNICO-RACIAIS NO BRASIL}

Resumo:O texto aborda a particularidade da questão social no Brasil como fruto das relações capitalistas aqui construídas através da exploração e opressão das classes trabalhadoras. Busca a gênese das desigualdades e pauperismo no Brasil, marcado por quase quatro séculos de escravismo. Analisa os pilares de sustentação do escravismo: o trabalho escravo, a monocultura e o latifúndio, que geraram a riqueza, destacando que, após a abolição e da proclamação da república, com a necessidade construção de uma ideia de nação desenvolvida, era necessário eliminar o elemento negro, através da ideologia do branqueamento e do mito da democracia racial, que mascararam/mascaram a real condição a que foram postos negros e negras neste país.

Palavras-chave: Questão Social, racismo, trabalho, classes, escravidão

\section{SOCIAL ISSUE AND THE ETHNIC-RACIALS RELATIONS IN BRAZIL}

Abstract: The text deals with the particularity of the social issue in Brazil as a result of capitalist relations built here through exploitation and oppression of the working classes. It seeks the genesis of inequalities and pauperism in Brazil, marked by nearly four centuries of slavery. Analyzes the supporting pillars of slavery: slave labor, the monoculture and the landlordism, which generated high profit rates, highlighting that, after the abolition and the proclamation of the republic, with the need of construction of an idea of developed nation, it was necessary to eliminate the black element, through the whitening ideology and the myth of racial democracy, which masked / masks the real condition that were put black men and women in this country.

Keywords: Social Issue, racism, work, classes, slavery. 


\section{INTRODUÇÃO}

A hipótese trabalhada neste texto é de que a questão social no Brasil não pode ser analisada sem considerar as complexas relações étnico-raciais que estão na base da formação social brasileira, marcada por profundas desigualdades econômicas, sociais, políticas e culturais, fruto de quase quatro séculos de trabalho escravizado. Nesse período, foram traficados para o país cerca de 10 milhões de homens, mulheres, crianças do continente africano, que foram incorporados ao sistema colonial escravista. Estes produziram a riqueza do país no período e, com o fim da escravidão legal (1888) e início da República (1889) não foram incorporados ao sistema de produção como força de trabalho livre. Assim, partimos da análise de que não se pode pensar a questão social na sociedade brasileira contemporânea, sem recorrer à gênese do pauperismo, que está intrinsecamente ligada, como herança, às relações étnico-raciais que se conformaram neste país. Trata-se de apreender a particularidade desse fenômeno.

Seguramente, a história oficial, contada do ponto de vista dos dominantes, oculta a maior parte da existência do país desde a invasão do território pelos europeus, as relações construídas a partir do trabalho escravizado indígena e negro. Omite também que, quando as condições internas e externas para a exploração despudorada dos africanos e seus descendentes já não estavam mais postas, trataram de construir processos para uma transição à sociedade urbano-industrial, que excluiu os ex-escravizados indígenas e negros de qualquer acesso aos meios de produção, principalmente a terra, que fossem integrados como força de trabalho livre, bem como a restrição aos bens, serviços, direitos ou políticas protetivas que os identificassem dentro da cidadania construída na recente nação capitalista.

Compreender a raiz dos conflitos que geram a questão social no Brasil, a partir da composição e dinâmica de classes e relações étnicos-raciais"; contribuir com as elaborações do Serviço Social, para desvelar os mecanismos que constituiram o Brasil como uma sociedade profundamente desigual, com uma estrutura de classes também extremamente racializada, mas onde há grande dificuldade de compreender os conflitos sociorraciais e xenófobos que vigoram na atualidade, fruto dos mecanismos ideológicos construídos, são nossos objetivos.

2 DESIGUALDADES E QUESTÃO RACIAL: negros e negras na estrutura da sociedade brasileira.

O Brasil é um país rico, mas com extraordinárias desigualdades. Possui atualmente uma população de 190.732.694 habitantes, segundo o censo IBGE 2010. Conquistou o espaço de $7^{\mathrm{a}}$ economia do mundo, com um Produto Interno Bruto (PIB) de US\$ 2,48 trilhões de dólares, superior ao PIB do Reino Unido. Do ponto de vista da natureza é extremamente privilegiado, possui uma área territórial de 8,5 milhões de $\mathrm{km}^{2}$ e uma costa marinha de 3,5 milhões de $\mathrm{km}^{2}$. Neste país está situada a maior parte da Floresta Amazônica, com a maior bacia hidrográfica do mundo, cujo principal rio é o Amazonas com $6.500 \mathrm{~km}$ de extensão, tendo como principais afluentes os rios: Japurá, Negro e Trombetas (margem esquerda) e Juruá, Madeira, Purus, Xingu e Tapajós (margem direita).

Toda essa riqueza tem colocado a Amazônia numa posição de grande importância para o planeta, considerando as condições climáticas atuais em face de cerca de dois séculos de industrialização de um lado e, por outro, a abundância de minérios, fauna e flora, necessários ao mercado mundial. Há outras bacias, não menos importantes: Araguaia-Tocantins, Paraíba, São Francisco, Paraná, Paraguai, Paraíba do Sul e Uruguai. Além dos dois maiores aquíferos do mundo: Alter do Chão e Guarani. O Brasil possui $13 \%$ das reservas de água doce do planeta. Neste país encontra-se também a região do Pantanal, que é a maior planície inundável do planeta, e a Mata Atlântica, que é a floresta tropical pluvial. Conta ainda com uma enorme área de cerrado e caatinga.

Todos esses elementos naturais combinados, somado ao clima com temperaturas elevadas e alto índice pluviométrico, favorecem a uma riquíssima biodiversidade, alta capacidade de produção de energia, elevado potencial de terras disponíveis para agricultura e pecuária. Vale destacar as grandes reservas minerais: ferro, ouro, cobre, manganês, bauxita, níquel, cassiterita, nióbio, diamante, esmeralda, platina, etc; as reservas de petróleo, inclusive a camada de pré-sal, nas reservas do quadrilátero ferrífero de Minas Gerais, da Serra do Urucum em Mato Grosso do Sul, Carajás no Pará, Barreirinhas no Maranhão; o gás natural e a possibilidade de produção da chamada energia limpa e biogás.

Do ponto de vista da indústria, o país desenvolveu um diversificado parque industrial, construindo uma indústria de base: aço, energia, portos, estradas, telecomunicações, durante muito tempo sob controle do Estado, além da indústria de bens de consumo duráveis e de produção. O país constituiu um dos maiores proletariados industriais não só da América Latina, mas do mundo. Na década de 1970 , sob o regime militar, com modernização tecnológica concentrada no sul e sudeste brasileiro, crescimento da proletarização, urbanização desordenada, o crescimento de bens de consumo duráveis, a expansão capitalista no meio rural, a classe trabalhadora brasileira duplicou de cerca de 7,7 milhões para 14,3 milhões, representando $33 \%$ da população economicamente ativa.

Apesar de ser um território extremamente rico e privilegiado pela natureza, do ponto de vista 
social e econômico apresenta graves problemas que levam a maioria da população que nele reside a viver em condições grandes de necessidades. Sendo a $7^{a}$ economia mundial é, por outro lado, uma das economias mais desiguais do mundo: está entre os 12 mais desiguais no ranking e o primeiro lugar na América Latina. Essa é uma contradição que precisa ser desvelada. Ainda mais quando se trata da situação das populações não-brancas, em especial negros e indígenas, os dados oficiais são extremamente reveladores de que a desigualdade social e econômica no Brasil são profundamente racializadas.

O censo demográfico de 2010 , da população de 190.732.694 pessoas, 97 milhões se declaram pretas e pardas e 91 milhões se declaram brancas, do total $0,7 \%$ indígenas ou amarelos. Ou seja, os não brancos compõem pouco mais da metade da população. Segundo o Instituto de Pesquisa Econômica Aplicada (2008) entre os $10 \%$ mais pobres do país, $65 \%$ são negros. Já entre os $10 \%$ mais ricos, $86 \%$ são brancos.

Do ponto de vista do Índice de Desenvolvimento Humano, dados da ONU de 2009 mostram que o Brasil ocupava a $75^{\mathrm{a}}$ posição, entre os 182 países. Porém, há uma diferença entre os indicadores para os brancos, onde o país ocuparia $046^{\circ}$ lugar e para os negros cuja colocação subiria para a $105^{\text {a }}$ posição. Esse dado da posição do Brasil negro revela o quão vulnerável está a população afrodescendente. Por exemplo, segundo o IPEA (2008) existem 16,2 milhões de brasileiros $(8,5 \%)$ que sobrevivem com menos de $\mathrm{R} \$ 70,00 /$ mês. Desses $8,5 \%, 70,8 \%$ são negros. $63 \%$ da população que vive abaixo da linha de pobreza é negra e o mesmo ocorre com a condição racial dos $70 \%$ que vivem abaixo da linha de indigência.

Pesquisa do IBGE de 2010 mostra que a média salarial dos brancos é de $R \$ 1.538,00$, dos pardos $R \$ 845,00$, dos negros $R \$ 834,00$ e dos indígenas é de $R \$ 735,00$.

Essa situação é mais dramática quando trazemos os dados sobre a mulher negra, cuja média salarial é pouco acima da metade da média de um homem negro, ou um terço de um homem branco. Dados de 2009 revelavam que $37,6 \%$ dos domicílios chefiados por trabalhadoras domésticas se encontravam abaixo da linha de pobreza.

Pesquisa do Dieese/Seade mostra que o negro ganha em média $\mathrm{R} \$ 5,81$ por hora trabalhada, enquanto não-negros recebem $R \$$ 9,62. Negros recebem, média, $60,4 \%$ do valor pago a outros grupos raciais. A pesquisa avança mostrando que os determinantes para essa diferença é a maior precarização e a presença do negro em postos de trabalho menos especializados. Por exemplo, em 2010, 8,8\% dos negros estavam na construção civil, sendo que dos não-negros estavam $5 \%$. Já no serviço público os dados se invertem: $8,4 \%$ dos ocupados não-negros, contra $6,2 \%$ de negros.
No que diz respeito à Educação os dados são dramáticos, principalmente se considerarmos que através da educação as populações mais pobres têm esperança na mobilidade social. No Brasil, a taxa de analfabetismo é de 10,3\%; somente $26 \%$ da população são plenamente alfabetizados; $34 \%$ dos estudantes do ensino médio estão em distorção idade-série e a média de estudo é de 7,2 anos. Entretanto, quando buscamos os dados em relação à população negra encontram-se diferenças abismais. Em relação à taxa de analfabetismo, entre a população branca é de $5,9 \%$ para pessoas com 15 anos ou mais, entre os negros os números crescem para $14,4 \%$, e entre os pardos, de $13 \%$. Nas cidades pequenas, com até 5.000 habitantes, o analfabetismo entre os negros atinge $27,1 \%$. Entre 2000 e 2010, o número de analfabetos com 15 anos de idade ou mais recuou de $13,63 \%$ para $9,6 \%$.

Do ponto de vista da Educação, dados do IBGE, de 2004, mostravam que dos $29,4 \%$ brasileiros considerados oficialmente analfabetos $80 \%$ eram negros. Já o IPEA (2008) mostrava que em termos nacionais, $23,1 \%$ da população branca possui 12 anos ou mais de estudo, já a população negra em tal situação era de apenas $8,3 \%$. Ainda segundo esse Instituto, no ensino médio, o número de jovens brancos é $44,5 \%$ maior que o de negros. Pesquisa realizada pelo Laboratório de Políticas Públicas da UERJ (LPP), também em 2004, esclarecia que dos brasileiros que concluíram o Ensino Médio 67,6\% eram brancos, $4,3 \%$ eram negros, $26,5 \%$ pardos e $0,9 \%$ amarelos.

Com relação ao Ensino Superior os dados são ainda mais esclarecedores. Na pesquisa do LPP, baseada no Censo 2000 , foi verificado que apenas 5,8 milhões de brasileiros possuem diploma na educação superior, o que equivale a $6,77 \%$ da população com mais de 25 anos. O surpreendente é que destes poucos, somente $2,1 \%$ se identificam como negros, enquanto $82,8 \%$ se identificam como brancos e $12 \%$ como pardos. Apenas $18 \%$ de doutores são negros, enquanto os brancos representam $86,4 \%$ dessa categoria. O estudo aponta ainda dados sobre as profissões com maior dificuldade de acesso para negros e negras: Medicina, advocacia, engenharia, entre outras. $\mathrm{O}$ caso dos médicos é emblemático: dos 286 mil médicos identificados no censo 2000, $86 \%$ eram brancos, sendo verificado que seriam preciso pelo menos 25 anos de reserva totais de vagas de todos os cursos de medicina do Brasil para não brancos (negros, pardos, indígenas) para termos uma proporção equilibrada entre médicos brancos e negros. Esses dados mostram o profundo abismo separando brancos e negros com relação à educação.

Dados do IPEA, em 1992, mostravam que apenas $1,5 \%$ dos jovens negros nesta faixa etária estavam na universidade. Em 2009, eram 8,3\%. Entre os jovens brancos, as matrículas líquidas triplicaram no mesmo período - de $7,2 \%$ para $21,3 \%$. 
A frequência dos jovens negros na universidade, que correspondia a $20,8 \%$ da frequência dos brancos em 2002, passou a corresponder a 38,9\% em 2009. Esse aumento é resultante da política de cotas estabelecida principalmente nas universidades federais.

Em relação à saúde, os dados mostram que no Brasil há disponível apenas 2.26 leitos por cada mil habitantes. A taxa de mortalidade infantil é de $17,56 \%$ a cada mil nascidos vivos. Analisando esses dados mais minuciosamente do ponto de vista dos grupos étnicos que compõem a população brasileira, os dados são ainda mais dramáticos. O Atlas Racial Brasileiro, lançado pelo Programa das Nações Unidas para o Desenvolvimento (PNUD), lançado em 2005, revelou que a taxa de mortalidade infantil até um ano de idade é $66 \%$ maior entre as crianças negras. Outro dado alarmante, por exemplo, é que cerca de 2,6 mulheres afrodescendentes morrem por dia, contra 1,5/dia das mulheres brancas. A expectativa de vida de um homem negro no Brasil é seis anos menor que a de um homem branco. Em relação à violência os dados são aterradores. Calcula-se que a possibilidade de um adolescente negro ser vítima de homicídio é 3,7 vezes maior em comparação com os brancos. As maiores vítimas de homicídios no Brasil são homens jovens e negros, "[...] numa proporção $135 \%$ maior do que os nãonegros: enquanto a taxa de homicídios de negros é de 36,5 por 100 mil habitantes. No caso de brancos, a relação é de 15,5 por 100 mil habitantes". Isso tem como consequência, segundo a pesquisa, uma perda de expectativa de vida devido à violência letal $114 \%$ maior para negros, em relação aos homicídios: "Enquanto o homem negro perde 1,73 ano de expectativa de vida (20 meses e meio) ao nascer, a perda do branco é de 0,71 ano, o que equivale a oito meses e meio." Em 2002, o índice nacional de vitimização negra foi de 45,8 . Isto é, nesse ano, no país, morreram proporcionalmente $45,8 \%$ mais negros do que brancos. No de 2006: morreram $82,7 \%$ mais negros do que brancos. Já em 2010, um novo patamar preocupante: morrem proporcionalmente $139 \%$ mais negros que brancos, isto é, bem acima do dobro. Proporcionalmente, por ano, morrem cerca de $139 \%$ mais negros do que brancos. A cada 25 minutos morre um jovem negro de forma violenta no Brasil (Secretaria Especial de Promoção de Políticas pela Igualdade Racial). Entre 2002 a 2008: O número de vítimas brancas caiu de 18.852 para 14.650, o que representa uma significativa diferença negativa, da ordem de $22,3 \%$. Já entre os negros, o número de vítimas de homicídio aumentou de 26.915 para 32.349 , o que equivale a um crescimento de $20,2 \%$.

Os próprios dados oficiais demonstram a condição social e econômica dessa população. Quais os determinantes dessa situação? Podemos afirmar que questão social e questão racial estão profundamente inter-relacionadas no Brasil? Como o Serviço Social tem enfrentado esse debate?
De modo geral temos acordo com a perspectiva análitica da questão social que credita o seu surgimento a partir da emersão da sociedade urbano-industrial, com as mudanças na forma de produzir e reproduzir a vida social, calcada na relação capital/trabalho e todas as consequências advindas desse processo: exploração, opressão, péssimas condições de trabalho e vida do proletariado. Isso conduziu os proletários a enfrentamentos com a classe antagônica - a burguesia, exigindo o seu reconhecimento como classe portadora de direitos.

Corretamente, Netto (2001) afirma que mesmo a questão social estando intrinsecamente ligada à exploração capitalista, ou seja, é própria da sociedade burguesa, do desenvolvimento capitalista, isto não implica que não haja outros elementos que a componham.

A análise de conjunto que Marx oferece n'O capital revela, luminosamente, que a "questão social" está elementarmente determinada pelo traço próprio e peculiar da relação captal/trabalho-a exploração. A exploração, todavia, apenas remete à determinação molecular da "questão social"; na sua integralidade, longe de qualquer unicausalidade, ela implica a intercorrência mediada de componentes históricos, políticos, culturais, etc. Sem ferir de morte os dispositivos exploradores do regime do capital, toda luta contra as suas manifestações sóciopolíticas e humanas (precisamente o que se designa por "questão social") está condenada a enfrentar sintomas, consequencias e efeitos. (NETTO, 2001, p. 45-46).

É nesse aspecto trabalhado por Netto (2001), da não unicausalidade no trato da questão social, ou seja, não apenas pela determinação econômica, que queremos aprofundar, entendendo que o capitalismo é global, regido pelas mesmas leis, determinações e contradições seja no Japão, EUA, Peru, Angola ou Brasil. Porém, as manifestações da questão social se revelam tendo em vista componentes históricos, sociais, culturais, etc.

Aqui trata-se de buscar a gênese que particulariza a questão social no Brasil a partir da constituição da formação social brasileira, que tem como marca histórica o escravismo. Não se trata de afirmar que no período escravismo no Brasil tivemos a mesma dinâmica capitalista do pós 1930, portanto, que tenhamos uma questão social no período do escravismo pleno e tardio, utilizando uma classificação de Moura (1987). Mas, compreender que o processo do escravismo negro, a partir da diáspora africana é parte da dinâmica que resultou na acumulação capitalista, principalmente na América, servindo ao desenvolvimento do capitalismo industrial na Europa. 
Como afirma Mandel (1980, p. 58), analisando o surgimento das classes sociais no capitalismo:

Os capitalistas, quanto à origem social poderiam ter sido comerciantes, antigos nobres ou mestres artesãos enriquecidos, ou até servos libertados, contudo, o relevante é de onde vieram os capitais: do capital comercial e usurário; da colonização violenta da Ásia, África e América, primeiro através da pilhagem de metais preciosos, depois como fornecedores de matérias-primas para a grande indústria e alimentos para seus trabalhadores, através das grandes plantações sob regimes escravistas.

Mandel (1980), assim como as análises marxianas, mostram o quão conectadas com a acumulação primitiva de capital e com o mercantilismo estavam as regiões, ditas bárbaras, ao sistema capitalista global em desenvolvimento. Como a diáspora africana contribuiu decisivamente através do tráfico negreiro e da exploração descarada de homens, mulheres e crianças escravizadas, arrancadas de suas terras, para a acumulação de capitais.

O descobrimento das regiões auríferas e argentíferas na América, o extermínio, a escravização e o soterramento nas minas da população indígena, a conquista e saque das Índias Orientais, a transformação da África em um quintal reservado para o comércio de peles negras caracterizavam 0 alvorecer da era de produção capitalista. Esses processos idílicos constituem fatores fundamentais da acumulação primitiva do capital. Os atos de barbárie e os perversos ultrajes perpetrados pelas chamadas raças cristãs em todas as regiões do mundo e contra todos os povos que puderam subjugar, não encontram paralelo em nenhuma época da história universal e em nenhuma raça, por mais selvagem e inculta, impiedosa e impudica que fosse. (MANDEL, 1980, p. 57).

O Brasil, como toda a América Latina, desde seus primórdios, se constituiu a partir dessas relações de subordinação e pilhagem.

A Europa necessitava de ouro e prata. Os meios de pagamentos em circulação se multiplicavam sem cessar e era preciso alimentar os movimentos do capitalismo na hora do parto: os burgueses se apoderavam das cidades e fundavam os bancos, produziam e trocavam mercadorias, conquistavam novos mercados. Ouro, prata, açúcar: a economia colonial mais abastecedora que consumidora, estruturou-se em função das necessidades do mercado europeu, e a seu serviço. $O$ valor das exportações latino americanas de metais preciosos foi, durante prolongados períodos do século XVI, quatro vezes maior que as importações, composta por escravos, sal e artigos de luxo. Os recursos fluíam para que os acumulassem as nações europeias emergentes do outro lado do mar. Esta era a missão fundamental que trouxe os pioneiros, embora, além disso aplicassem o evangelho quase tão frequentemente como o chicote, aos índios agonizantes. A estrutura das colônias ibéricas nasceu subordinada ao mercado externo e, em consequência, centralizada em torno do setor exportador que concentrava renda e poder. (GALEANO, 1986, p. 22)

Fica explícita a intenção dos colonizadores, principalmente portugueses e espanhóis, em explorar as riquezas naturais desde os minérios (ouro, prata, etc.), especiarias, pau-brasil, borracha etc. passando pela monocultura do algodão, açúcar, café, recorrendo à força de trabalho escravizada indígena e africana, que servia à expansão da indústria na Europa e para a acumulação primitiva. No Brasil colônia a economia sustentou seus pilares no trabalho escravo, na monocultura e no latifúndio. Como discute Santos (2010, p. 21).

O advento da atividade açucareira veio substituir os tipos iniciais de exploração da colônia baseados no sistema extrativista de produtos como o pau-brasil (FERLINI, 1994). Com a produção do açúcar inaugurava-se o sistema produtivo de exploração, sendo o latifúndio, a monocultura e o trabalho escravo elementos essenciais para a diminuição dos gastos e aumento dos lucros (NOVAIS, 2001). A grande extensão territorial evitava gastos com fertilização e cuidados técnicos. A monocultura impedia o crescimento da pequena propriedade que não interessava à metrópole; e, o trabalho escravo se impunha por algumas razões. Dentre elas a existência de um tráfico ultramarino de escravos era o que mais justificava, pois conforme nos mostra. Novais (2001) possibilitava enormes lucros à metrópole e isso determinou a substituição do trabalho escravo indígena pelo trabalho escravo africano. As riquezas que a coroa portuguesa e os comerciantes de escravos angariavam com o tráfico tornavam esta atividade, e por consequência o trabalho escravo africano, indispensáveis à dinâmica das relações entre metrópole e colônia. 
Para justificar essa exploração aviltante, os europeus recorreram a diferentes justificativas de diversas ordens, inclusive argumentando cientificidade. Como afirma Moura (apud SANTOS, 2010)

[...] o negro passou a ser definido como inferior, bárbaro, selvagem, assemelhado a um animal, simples instrumento de produção, Ihe foi retirada sua verticalização e humanização através da violência física e psicológica.

Como discute Moura (1994, p. 68), é preciso fazer a distinção em essência da condição do escravo para a condição do trabalhador livre, mesmo que este último tenha sido igualmente vítima de castigos físicos brutais no início do capitalismo na Europa.

Era, por isso mesmo, malgrado as condições opressivas a que estava submetido, um ser livre, isto é, um ser que não era dono apenas da sua interioridade (o corpo do escravo pertencia ao ser senhor), mas dispunha livremente do seu corpo para locomoverse e atuar como agente produtor. Essas regras, mesmo nas condições odiosas expostas acima, tinham de ser respeitadas porque o mercado não podia ser criado independentemente dele, mesmo com a existência do mercado industrial de reserva. É verdade que a mercadoria (por ele produzida) não the pertencia, mas ele ao imprimir nela o seu trabalho, criando valor, participava do mercado no nível em que recebia um salário que também agia ativamente no mercado. Já o escravo circulava como mercadoria, idêntica àquela a qual ele próprio produzia. E é nesse nível de relações econômicas que o escravo é socialmente coisificado.

Interessa-nos reter que a produção escravista criou igualmente uma cultura escravista, valores, moral, ética, cultura, correspondentes, que marcou profundamente a dinâmica do desenvolvimento socioeconômico e cultural do Brasil pós-escravidão.

Marx e Engels afirmam no Manifesto Comunista que As ideias dominantes de uma época sempre foram as ideias da classe dominante. Já em Contribuição à Crítica da Economia Política assinala.

$\mathrm{Na}$ produção social de suas vidas, os seres humanos ingressam em relações determinadas, necessárias, independentes da sua vontade, relações de produção essas que correspondem a um determinado nível de desenvolvimento de suas forças produtivas materiais. $O$ conjunto dessas relações de produção forma a estrutura econômica da sociedade, a base real, sobre a qual se ergue uma superestrutura jurídica e política e à qual correspondem determinadas formas sociais de consciência. $O$ modo de produção da vida material condiciona, em geral, o processo de vida social, político e espiritual. Não é a consciência dos homens que determina o seu ser, mas sim, inversamente, é o seu ser social que determina a sua consciência. Em certo nível de seu desenvolvimento, as forças produtivas materiais da sociedade entram em contradição com as relações de produção existentes ou - o que destas é apenas uma expressão juridica - com as relações de propriedade, no interior das quais se haviam movimentado até então. (MARX, 1983, p. 24)

No mesmo sentido, Silva (1995 apud SANTOS, 2010, p. 25), analisa o aspecto ideológico que justifica a exploração do homem pelo homem, no caso do escravismo negro.

Como não é possível estabelecer relações recíprocas de direitos $\mathrm{e}$ respeito em um sistema baseado na exploração do outro, desenvolveu-se toda uma ideologia justificadora da opressão e inferiorização, objetivando a destruição da identidade, da autoestima e do reconhecimento dos valores e potencialidades do oprimido.

Evidentemente que a dinâmica social brasileira não se deu sem conflitos e resistências tanto indígena como negra. Conforme defende Moura, apesar das adaptações de setores da população escravizada ao sistema e de lutas de setores não escravizados, o conflito central que moveu o aparato estatal foi entre os negros e os senhores. A quilombagem, assassinatos de senhores, fugas, infanticídio, etc. foram formas encontradas pelos negros para resistirem à opressão. Porém, não foram capazes de criar uma alternativa de ordem societal em substituição à existente. Nesse aspecto, há que ressaltar que foram as relações sociais burguesas que encontraram condições para o pleno desenvolvimento das forças produtivas na América Latina, e em particular, no Brasil, a partir da sua tendência global e globalizante.

Assim, mesmo com as pressões externas, principalmente da Inglaterra, a quem não mais interessava a escravidão, pois precisava de mercados para seus produtos manufaturados, assim como as pressões internas dadas pela luta quilombola, pelo avanço do abolicionismo, rebeliões (Revolta dos Malês, Cabanagem, Balaiada, entre outras), os escravocratas conseguiram preparar o terreno para a passagem sem grandes traumas ao sistema de trabalho livre. Um dos poderosos 
instrumentos foi a Lei de Terras de 1850, ou seja, próximo à abolição, foi editada num país em que o acesso à terra era mediante sesmaria e capitanias hereditárias, passando a ser mediante compra e venda. Isso numa evidente negação do acesso à população negra, que em 1888 será libertada, sem indenizações, sem reparações pelos quase quatro séculos de escravidão, e sem acesso aos bens, serviços e mínimo de sistema protetivo.

Se analisarmos mais detidamente não apenas esta passagem do poder decisório sobre a aquisição da terra, mas o seu significado sociológico mais importante ao propiciar possibilidades de contratos àquelas camadas que poderiam adquiri-la através da compra - populações livres - poderemos concluir que, à medida que se afastou do poder público o poder público do dever social de doar aos ex-escravos (quando saíssem do cativeiro) parcelas de terras às quais às quais tinham direito 'por serviços prestados' e nas quais pudessem integrar-se, como proprietários, na conclusão do processo abolicionista, criou as premissas para a marginalização social.

Com essa lei os escravos beneficiados com a Abolição ficariam impedidos de exigir ou solicitar terras ao poder imperial como indenização conseguida 'por direito' durante a escravidão. Por outro lado, possibilitava ao colono estrangeiro, pelo menos teoricamente, através dos seus recursos monetários ou com a ajuda da comunidade da qual eram originários, ou órgãos de solidariedade, de adquiri-las para si e para a sua família [...].

A Lei da Terra tinha, no fundo, um conteúdo político. Ela deu um cunho liberal à aquisição de terras no Brasil, mas visava impossibilitar uma lei abolicionista radical que incluísse a doação pelo Estado de parcelas de glebas aos libertos, e, de outro, estimular o imigrante que via, a partir daí, a possibilidade de transformar-se em pequeno proprietário, aqui chegando." (MOURA, 1994, p.71)

Como afirma Santos (2010, p. 23)

O fim da mesma e o início do sistema capitalista de produção não representaram para a população negra brasileira uma melhoria das suas condições de vida que permaneceram extremamente precárias. Os ex-escravos e seus descendentes continuaram a ser tratados como inferiores e discriminados pela cor da pele, relegados á miséria e falta de perspectivas.
A transição do escravismo para o capitalismo urbano-industrial, dessa forma, ocorreu sem grandes rompimentos, excluindo a população liberta. Em relação a essa transição, Moura destaca que não afetou os interesses das oligarquias latifundiárias que conservou seus interesses e privilégios e a modernização a serviço de uma estrutura arcaica.

A passagem da escravidão para o trabalho livre não afetou por isto os interesses das oligarquias, pois ao perderem escravos, muitos deles já onerosos por serem membros de um estoque envelhecido, continuaram com a posse da terra, símbolo econômico e social do poder. E essa tática apelou para uma solução alternativa que permitisse a essa oligarquia continuar na posse da terra: a vinda dos imigrantes. (MOURA, 1994, p. 58).

Após a abolição, se do ponto de vista econômico foram operadas mudanças significativas, do ponto de vista social pouca coisa mudou para os ex-escravizados. Na substituição pelo trabalho livre, a classe dominante brasileira tratou de incorporar imigrantes, que também vieram em condições deploráveis de exploração e de repressão às suas lutas, excluindo a força de trabalho negra.

Os escravos, estavam excluídos do processo de mobilidade social, bloqueados pela sua condição de cor e classe e por isto mesmo impossibilitados de competir nesse processo de modernização na área de trabalho. (MOURA, 1994, p. 68)

Importante destacar ainda que com a Proclamação da República, em 1889, a necessidade de a construção do projeto de nação à imagem e semelhança das nações europeias, a numerosa população negra representava uma ameaça ao ideal de nação branca. Daí a ideologia da mestiçagem, com o intuito de num determinado interstício abolir os traços negroides da população brasileira.

A vitória na luta pela vida, entre nós, pertencerá no porvir (futuro), ao branco; mas para essa mesma vitória (o branco) tem necessidade de aproveitar-se do que de útil as outras duas raças the podem fornecer; máxime a preta, com que tem mais cruzado. Pela seleção natural, todavia depois de prestado auxílio de que necessita, o tipo branco irá tomando a preponderância até mostrar-se puro e belo como no velho mundo. Será quando já estiver de todo aclimatado no continente. Dois fatos contribuirão largamente para esse resultado: de um lado, a extinção do tráfico negreiro e o desaparecimento constante dos índios, 
e de outro a imigração europeia. (SILVIO ROMERO apud Silva, 2012)

A constituição orgânica do negro, modelado pelo habitat físico e moral em que se desenvolveu, não comporta uma adaptação à civilização das raças superiores, produtos de meios físicos e culturais diferentes. (RODRIGUES, 1987)

A ideologia do branqueamento, "[...] nada mais é do que uma tática para desarticular ideologicamente e existencialmente o segmento negro a partir de sua auto-análise" (MOURA, 1983, p. 126), completada pelo mito da democracia racial que pregava a inexistência do conflito racial, onde a pluralidade étnico-racial e democracia conviviam perfeitamente, colocaram um véu mistificador na situação perversa em que foi posta a população negra neste país.

\begin{abstract}
A divisão racial do trabalho durante a escravidão seria substituída pela "competição democrática" da sociedade capitalista. Tal pensamento escamoteava a construção histórica do país e virava as costas à condição da população negra durante essa formação. Essa competição democrática consubstanciada no mito da democracia racial "desarticula a consciência do negro brasileiro", pois o mesmo se vê como incapaz frente ao sucesso profissional e educacional do branco. (MOURA, 1983, p.127)
\end{abstract}

\section{CONCLUSÃO}

Para efeito deste artigo e pelo percurso histórico feito, conclui-se que o racismo foi uma ideologia, calcada na materialidade do sistema escravista no Brasil, criada para submeter e dividir a população trabalhadora e assim, garantir a exploração, a opressão e humilhação. Quase quatro séculos de escravismo, deixaram marcas profundas na sociedade brasileira, que são visíveis até os dias atuais. O racismo foi estruturante da sociedade brasileira, construção histórica do Estado, para justificar a exploração despudorada de homens, mulheres e crianças arrancados da África, assim como de seus descendentes.

O Brasil é uma sociedade das mais desiguais do mundo, mesmo sendo atualmente a $7^{\mathrm{a}}$ economia. Desigualdades sociais e econômicas que foram aprofundadas terrivelmente nas últimas duas décadas, a partir das políticas neoliberais adotadas principalmente a partir do Governo Collor de Melo, Fernando Henrique Cardoso, Lula da Silva e Dilma Rousseff.

Evidentemente que a formação sócio-histórica do nosso país, desde a sua gênese, criou uma situação estrutural de desigualdades que, mesmo com as intensas lutas sociais desenvolvidas pelos setores desfavorecidos, que garantiram algumas conquistas e direitos, não as reverteram.

Os dados oficiais mostram as diferenças colossais existentes entre brancos e não brancos, onde as populações negra e indígena ocupam os espaços mais desprivilegiados na sociedade e os piores indicadores de condições de vida e trabalho em todos os itens.

Sem dúvidas, as classes sociais no Brasil são extremamente racializadas. A discriminação racial só foi reconhecida oficialmente em 1951, através da Lei Afonso Arinos, reconhecida como crime inafiançável e imprescritível (incluso no Artigo $5^{\circ}$, inciso XLII, da Constituição de 1988), sujeitando os responsáveis à pena de reclusão.

Apesar de muitas lutas e resistências, e de muitos reconhecimentos legais, a exemplo da Lei 10.639, que institui o ensino de História da África e dos Africanos no Brasil, da instituição do Estatuto da Igualdade Racial (Lei no 12.288, de 20 julho de 2010), a instituição de cotas raciais e sociais nas instituições de ensino superior, pouco tem representado efetivamente mudanças na vida econômica e social dessas populações. As denúncias de um verdadeiro genocídio da população negra, as drogras (em especial o crack), a violência polícial, o número de afrodescendentes no sistema prisional, os variados projetos de lei que visam retirar as terras das populações originárias e remanescentes de quilombos, a exemplo da PEC 215, revelam que as políticas liberais implementadas não têm tido eficiência, no sentido de reverter a situação em favor dos mais vulneráveis.

Enfrentar essa realidade, entendendo seus determinantes, assim como construir propostas de enfrentamento, de organização e lutas constitui-se um grande desafio para o Serviço Social, movimentos sociais e para a sociedade como um todo, a fim de apontar para uma sociabilidade sem opressão e exploração, que respeite as diferenças.

\section{REFERÊNCIAS}

GALEANO, Eduardo. As veias abertas da América Latina. Rio de Janeiro: Paz e Terra, 1986

IAMAMOTO, Marilda. A Questão Social no Capitalismo. Temporalis, Porto Alegre , n. 3, 2001.

INSTITUTO BRASILEIRO DE GEOGRAFIA E ESTATÍSTICA. Censo demográfico. Rio de Janeiro, 1991. Disponível em < http://www.ibge.gov. br/censo/>. Acesso em: 23 out 2013.

Censo demográfico. Rio de Janeiro, 2000. Disponível em < http://www.ibge.gov.br/censo/>. Acesso em: 23 out 2013. 
Censo demográfico. Rio de Janeiro, 2010. Disponível em < http://www.ibge.gov.br/censo/>. Acesso em: 23 out 2013.

Desigualdades raciais e racismo e políticas públicas: 120 anos após a abolição. Brasília, DF, 2008. Disponível em: <www.ipea.gov. br>. Acesso em: 12 ago 2013.

Políticas sociais: acompanhamento e análise. Boletim de Políticas Sociais, Brasília, DF, n. 19, 2011. Disponível em: <http://www.ipea. gov.br/portal/images/stories/PDFs/politicas_sociais/ bps_19_completo.pdf>. Acesso em: 12 ago 2013.

UNIVERSIDADE DOESTADODO RIODE JANEIRO. Laboratório de Políticas Públicas. Programa Políticas da Cor na Educação Brasileira (RJ). Rio de Janeiro, 2013. Disponível em :http://www. politicasdacor.net. Acesso em: 6 nov 2013.

MANDEL, Ernest. Trotski: um estudo da dinâmica de seu pensamento. Rio de Janeiro: Zahar, 1980

MARX, Karl; ENGELS, Friedrich. Manifesto do Partido Comunista. São Paulo: Boitempo, 1998.

Contribuição à crítica da economia política. 2. ed. São Paulo: Martins Fontes, 1983.

MOURA, Clovis. Dialética Radical do Brasil Negro. São Paulo: Editora Anita, 1994.

PAULO NETTO, José Paulo. Cinco notas a propósito da questão social: a a questão social no capitalismo. Temporalis, Brasília, DF, n. 3, 2001.

PROGRAMA DAS NAÇÕES UNIDAS PARA O DESENVOLVIMENTO. Atlas Racial Brasileiro. Brasília, DF, 2004. Disponivel em: <http://www.pnud. org.br/publicacoes/atlas_racial/index.php>. Acesso em: 12 ago. 2013.

RODRIGUES, Raimundo Nina. Os africanos no Brasil [1932]. 2. ed. Revisão Homero Pires. São Paulo: Companhia Editora Nacional. (Série RVC, v. IX).

SANTOS, Rosenverck Estrela. Ações afirmativas em perspectiva marxista. Revista Universidade e Sociedade, Brasília, DF, n. 46, 2010.

SILVA, Wilson Honório. Globalização e racismo. São Paulo: ILAESE. 2012. Disponível em: <http:// www.ilaese.org.br/wp-content/uploads/2012/11/ ra\% C3\%A7a-e-classe-wilson-honorio-2012.pdf>. Acesso em: 12 ago. 2013.

\section{Cláudia Alves Durans}

Assistente Social

Doutora em Serviço Social pela Universidade Federal de Pernambuco (UFPE)

Professora da Universidade Federal do Maranhão (UFMA)

E-mail: cdurans@hotmail.com

Universidade Federal do Maranhão - UFMA

Cidade Universitária do Bacanga

Avenida dos Portugueses, 1966-Bacanga

85.085-580- São Luís-Ma 